\title{
Chronic nicotine treatment enhances vascular smooth muscle relaxation in rats
}

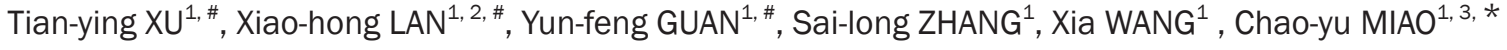 \\ ${ }^{1}$ Department of Pharmacology, Second Military Medical University, Shanghai 200433, China; ${ }^{2}$ Department of Pharmacy, 81th Hospital \\ of PLA, Nanjing 210002, China; ${ }^{3}$ Center of Stroke, Beijing Institute for Brain Disorders, Beijing 100069, China
}

\begin{abstract}
Aim: To investigate the effect of chronic nicotine treatment on vascular function and to identify the underlying mechanisms. Methods: Adult rats were treated with nicotine $\left(3 \mathrm{mg}^{\mathrm{kg}} \mathrm{kg}^{-1} \cdot \mathrm{d}^{-1}, \mathrm{sc}\right)$ for 6 weeks. After the rats were sacrificed, aortic rings were prepared for detecting vascular reactivity, and thoracic aorta and periaortic fat samples were collected for histological and molecular biology studies.

Results: Chronic nicotine treatment significantly reduced periaortic fat, and specifically enhanced smooth muscle relaxation without altering the aortic adventitial fat and endothelium function. Pretreatment with the soluble guanylyl cyclase inhibitor ODQ (3 $\mu$ mol/L) or PKG inhibitor Rp-8-Br-PET-cGMP (30 $\mathrm{mol} / \mathrm{L})$ abolished the nicotine-induced enhancement of smooth muscle relaxation, whereas the cGMP analogue 8-Br-cGMP could mimic the nicotine-induced enhancement of smooth muscle relaxation. However, the chronic nicotine treatment did not alter PKG protein expression and activity in aortic media.

Conclusion: Chronic nicotine treatment enhances vascular smooth muscle relaxation of rats via activation of PKG pathway.
\end{abstract}

Keywords: nicotine; vascular smooth muscle; nitric oxide; cyclic GMP-dependent protein kinase type I; endothelium; vasodilation; nitroprusside; acetylcholine; adipose tissues

Acta Pharmacologica Sinica (2015) 36: 429-439; doi: 10.1038/aps.2015.5; published online 23 Mar 2015

\section{Introduction}

Nicotine is a well-known compound with extensive and complex effects on the cardiovascular system ${ }^{[1]}$. Research on nicotine and nicotinic acetylcholine receptors (nAChRs) has revealed that the chronic effect of nicotine may differ from the acute effect ${ }^{[2-4]}$. To fully understand the role of nicotine, it is necessary to investigate its chronic effect. Recently, studies from our group and others on chronic nicotine exposure have reported several novel effects, such as enhancing insulin sensitivity $^{[2,5]}$, augmenting insulin-induced mitogenic signaling ${ }^{[6]}$, and improving cognition ${ }^{[7]}$.

Most studies on the vascular function of nicotine focus on its acute effect ${ }^{[8,9]}$, while studies on its chronic effect focused mainly on fetal and neonatal nicotine exposure ${ }^{[10-12]}$. One of the latter studies reported that prenatal exposure to nicotine led to an increase in the amount of periaortic adventitial fat in the offspring and impaired the inhibitory effect of adventitial

\footnotetext{
"The first three authors contributed equally to this work.

* To whom correspondence should be addressed.

E-mail cymiao@smmu.edu.cn

Received 2014-08-17 Accepted 2015-01-06
}

fat on vascular contraction ${ }^{[12]}$. However, our previous study on nicotine cessation and obesity demonstrated that chronic nicotine exposure in adult rats induces a significant reduction in periaortic adventitial fat after 6 weeks of nicotine treatment ${ }^{[13]}$. Given that the chronic nicotine effects on vascular function in adults are largely unknown, and the unanswered question of whether the decreased amount of periaortic fat in our chronic nicotine exposure rat model affects vascular function, we designed the present study.

Our results indicate that chronic nicotine exposure does not affect vascular adventitial fat and endothelium function, but specifically enhances vascular smooth muscle relaxation. This chronic nicotine effect on smooth muscle relaxation is mediated through a cGMP-dependent PKG pathway. Our findings reveal a novel effect of nicotine on vascular function and link nicotine to the nitric oxide relaxation pathway, thus contributing to a more comprehensive understanding of nicotine pharmacology.

\section{Materials and methods}

Animal care and use

Male, 9- to 10-week-old Sprague-Dawley rats were purchased 
from Sino-British SIPPR/BK Lab Animal Ltd (Shanghai, China) and allowed 1 week to acclimatize. All animals were maintained in a 12-h light/dark cycle with free access to food and water. They received humane care, and all study protocols were approved by the Institutional Animal Care and Use Committee of the Second Military Medical University, China.

\section{Animal treatment}

To study the effect of nicotine on aortic function, SpragueDawley rats aged 10-11 weeks were divided into two groups. The saline group received a subcutaneous injection of saline, and the nicotine group received a subcutaneous injection of nicotine $\left(3 \mathrm{mg} \cdot \mathrm{kg}^{-1} \cdot \mathrm{d}^{-1}\right)^{[5,13]}$. Drug dosage was adjusted once a week according to the body weight. Organ chamber studies were performed and tissue samples were collected for histological sections or molecular biology study after 6 weeks of treatment.

In time course study, Sprague-Dawley rats were treated as above mentioned and were sacrificed at 1 week, 3 weeks and 6 weeks respectively for organ chamber study.

\section{Organ chamber studies}

Aortic rings were prepared and vascular reactivity was measured using our previous methods ${ }^{[14-16]}$. The rats were anesthetized with sodium pentobarbital $(60 \mathrm{mg} / \mathrm{kg}$, ip). After opening the thoracic cavity, the descending thoracic aorta was immediately removed and placed in cold Krebs-Henseleit solution of the following composition (mmol/L): $\mathrm{NaCl} 118.4$, $\mathrm{KCl}$ 4.7, $\mathrm{CaCl}_{2} 2.5, \mathrm{MgSO}_{4} 1.2, \mathrm{KH}_{2} \mathrm{PO}_{4} 1.2, \mathrm{NaHCO}_{3} 25.0$, glucose 11.1 and $\mathrm{CaNa}_{2}$-EDTA 0.026, and aerated with $95 \% \mathrm{O}_{2}$ and $5 \% \mathrm{CO}_{2}$. Rat aorta was cut into $5 \mathrm{~mm}$-wide rings. Four types of rings were prepared in our studies: $\mathrm{F}+\mathrm{E}+$ : aortic rings with intact adventitial fat and endothelium, F-E+: aortic rings with intact endothelium but adventitial fat removed, $\mathrm{F}+\mathrm{E}-$ : aortic rings with intact adventitial fat but endothelium removed, F-E-: aortic rings without adventitial fat and endothelium. The aortic rings were suspended in conventional organ baths filled with $20 \mathrm{~mL}$ Krebs-Henseleit solution, maintained at $37^{\circ} \mathrm{C}$ and continuously aerated with $95 \% \mathrm{O}_{2}$ and $5 \%$ $\mathrm{CO}_{2}$. Changes in isometric tension were recorded using an IT1-25 transducer and an IOX computerized system (EMKA Technologies, Paris, France). Each aortic ring was allowed to equilibrate for $60 \mathrm{~min}$ at a resting tension of $2.0 \mathrm{~g}$.

In experiments designed to examine vascular contractility, aortic rings were exposed to cumulative concentrations of phenylephrine $\left(10^{-9}\right.$ to $\left.10^{-4} \mathrm{~mol} / \mathrm{L}\right)$. In experiments designed to examine vascular relaxation, aortic rings were precontracted with a single dose of phenylephrine $\left(3 \times 10^{-7} \mathrm{~mol} / \mathrm{L}\right)$ for $25 \mathrm{~min}$ and then exposed to cumulative concentrations of acetylcholine $\left(10^{-8}\right.$ to $\left.3 \times 10^{-4} \mathrm{~mol} / \mathrm{L}\right)$, sodium nitroprusside $\left(10^{-10}\right.$ to $\left.10^{-4} \mathrm{~mol} / \mathrm{L}\right)$, or 8 -Br-cGMP $\left(10^{-6}\right.$ to $\left.3 \times 10^{-4} \mathrm{~mol} / \mathrm{L}\right)$. Except in one experiment, aortic rings were precontracted with cumulative concentrations of phenylephrine $\left(10^{-9}\right.$ to $\left.3 \times 10^{-5} \mathrm{~mol} / \mathrm{L}\right)$, and then exposed to a single dose of $\mathrm{ACh}\left(3 \times 10^{-6} \mathrm{~mol} / \mathrm{L}\right)$ and SNP $\left(10^{-4} \mathrm{~mol} / \mathrm{L}\right)$ successively. In experiments designed to study the underlying mechanisms, aortic rings were generally preincubated with various blockers for $40 \mathrm{~min}$ before exposure to sodium nitroprusside. At the end of each experiment, acetylcholine $\left(3 \times 10^{-6} \mathrm{~mol} / \mathrm{L}\right)$ was used to verify the completely removal of endothelial cells from aortic rings.

\section{Western blotting analysis}

cGMP-dependent protein kinase (PKG) protein expression was examined by SDS-PAGE and immunoblotting as described previously ${ }^{[17,18]}$. Anti-PKG type I polyclonal antibody was from Stressgen (MI, USA). Goat anti-rabbit IgG:HRP (Stressgen, Ann Arbor, MI, USA) was used as the secondary antibody for PKG detection by enhanced chemiluminescence immunoblot analysis. Each experiment was repeated at least three times.

\section{Measurement of PKG activity}

Enzyme activity assay of PKG was performed according to the manufacturer's instructions (Genmed Scientifics Inc, Arlington, MA, Shanghai Branch) by coupling the formation of ADP to the reaction catalyzed by $\mathrm{PK}$ and $\mathrm{LDH}$ in the presence of phosphoenolpyruvate (PEP) with the oxidation of NADH ${ }^{[19]}$. Briefly, assays were conducted for $5 \mathrm{~min}$ at $30^{\circ} \mathrm{C}$ in a reaction mixture of final volume $100 \mu \mathrm{L}$ containing aortic medial lysate $(8 \mu \mathrm{L})$, MOPS (pH 7.5), EDTA, cGMP, magnesium acetate, ATP, PEP, NADH, PK, LDH, selective heptapeptide glasstide RKRSRAE and QKRPRRKDTP ${ }^{[20]}$. The disappearance of $\mathrm{NADH}$ was detected by measuring a decrease in extinction at $340 \mathrm{~nm}\left(\varepsilon=6220 \mathrm{M}^{-1} \cdot \mathrm{cm}^{-1}\right)$ spectrophotometrically. PKG enzyme activity was expressed as unit per milligram of protein (unit: $\mu \mathrm{mol} \mathrm{NADH} \mathrm{min}^{-1}$ ).

\section{Morphological examination}

Animals were weighed and sacrificed under anesthesia with pentobarbital sodium $(60 \mathrm{mg} / \mathrm{kg}$, ip). The thoracic cavity was opened immediately. The aorta was excised and rinsed in cold physiological saline. Just below the branch of the left subclavicular artery, a 20-mm-long segment of thoracic aorta and periaortic fat was harvested, blotted and weighed. Vascular morphometry was performed in a blind fashion using coded slides of 4-mm-thick histological sections stained with hematoxylin and eosin. Vascular morphometry was performed using computer-assisted image analysis, as previously described ${ }^{[21]}$. In each rat, four cross-sections of thoracic aorta were measured to calculate the mean values.

\section{Reagents}

The following drugs were used in this study (unless otherwise specified, all were obtained from Sigma-Aldrich): phenylephrine, sodium nitroprusside, 5-hydroxytryptamine, acetylcholine, $1 \mathrm{H}-[1,2,4]$ oxadiazo-lo[4,3-a]quinoxalin-1-one (ODQ), 8bromoguanosine- $3^{\prime}, 5^{\prime}$-cyclic monophosphate sodium salt (8-Br-cGMP), Rp-8-Bromo- $\beta$-phenyl-1, $\mathrm{N}^{2}$-ethenoguanosine $3^{\prime}$, $5^{\prime}$-cyclic monophosphorothioate sodium salt (Rp-8-Br-PETcGMP).

Drugs were dissolved initially in distilled deionized water (except for ODQ which was dissolved in dimethyl sulphoxide) 
to prepare a $10^{-2}$ or $10^{-3} \mathrm{~mol} / \mathrm{L}$ stock solution. Further dilutions were made in Krebs solution.

\section{Statistical analysis}

All data are reported as mean \pm SEM. Statistical analysis was performed with a two-tailed Student's unpaired $t$ test, except for the vascular reactivity study, for which two-way ANOVA for repeated measures was used to compare two curves. The threshold for statistical significance was $P<0.05$.

\section{Results}

Regulation of adventitial fat on vascular contraction and relaxation in rat aortas

Periaortic adventitial fat can inhibit vascular contraction, and this anticontractile effect is thought to be associated with adventitial fat-derived relaxing factor(s), called $\mathrm{ADRF}^{[22]}$. We compared phenylephrine-induced contractions in four types of rat descending thoracic aortic preparations, $\mathrm{F}+\mathrm{E}+$ (both fat and endothelium intact), F-E+ (fat removed and endothelium intact), F+E- (fat intact and endothelium removed), and F-E(both fat and endothelium removed). Periaortic fat demonstrated a significant anticontractile effect in preparations with endothelium (F+E+ vs F-E+, Figure 1A, Table 1), but this was markedly reduced in preparations without endothelium $(\mathrm{F}+\mathrm{E}-$ vs F-E-, Figure 1B, Table 1). The anticontractile effects of the fat appeared weaker than those of the endothelium (Figure 1C, F+E+ vs F+E-, or F-E+ vs F-E-, Table 1). The endothelial anticontractile effect was also reduced after removal of the fat (Figure 1C), indicating the existence of crosstalk between adventitial fat and endothelium leading to the inhibition on vascular contraction. We also investigated contractions induced by 5-hydroxytryptamine. Similarly, the contractions significantly increased after removal of the fat in preparations with endothelium (F+E+ vs F-E+, Figure 1D, Table 1). This anticontractile effect of fat became small in preparations without endothelium (F+E- vs F-E-, Figure 1E, Table 1). The anticontractile effect of the endothelium also decreased approximately $50 \%$ after removal of the fat, but was still stronger than the anticontractile effect of the fat (Figure $1 \mathrm{~F}, \mathrm{~F}+\mathrm{E}+$ vs F+E-, or F-E+ vs F-E-, Table 1). In addition, acetylcholine induced endothelium-dependent relaxation and sodium nitroprus- side induced endothelium-independent relaxation were not affected by periaortic fat (Figure $1 \mathrm{G}$ and $1 \mathrm{H}$, Table 1 ).

Chronic nicotine treatment does not alter adventitial fat and endothelial function or smooth muscle contraction, but specifically enhances smooth muscle relaxation in rat aortas

After 6 weeks of nicotine treatment, both periaortic fat weight and the area of the thoracic aortas were significantly reduced, while aortic weight and wall area remained unchanged (Figure 2A-2D). Phenylephrine induced contractions were measured in $\mathrm{F}+\mathrm{E}+$ and $\mathrm{F}-\mathrm{E}+$ aortic preparations, and there were no significant differences between the saline and nicotine groups. The anticontractile effects of the adventitial fat $(\mathrm{F}+\mathrm{E}+$ vs $\mathrm{F}-\mathrm{E}+)$ were also similar in the saline and nicotine groups (Figure 2E), indicating that periaortic fat reduction by nicotine does not affect the adventitial fat function.

Acetylcholine induced relaxation was further determined in F-E+ aortic preparations, and a significant increase was observed in the nicotine compared with the saline group (Figure 2F). Because the endothelium-dependent relaxation by acetylcholine is due to nitric oxide (NO) release from the endothelial cells and subsequently NO action on the underlying smooth muscle cells, additional experiments were performed to identify whether the effects could be localized to the endothelium or smooth muscle (Figure 2G). Phenylephrine induced contractions were not different in either F-E+ or F-Eaortic preparations between the saline and nicotine groups, and the anticontractile effects of the endothelium (F-E+vs F-E-) were also similar in both groups (Figure $2 \mathrm{G}$ and $2 \mathrm{H}$, Table 2). In addition to an increase in endothelium-dependent relaxation by acetylcholine, endothelium-independent relaxation by NO donor, sodium nitroprusside, were increased in the nicotine compared with the saline group (Figure 2G, 2I, and $2 \mathrm{~J}$ ), indicating that chronic nicotine treatment improves smooth muscle responses to NO. The above data (Figure $2 \mathrm{~F}-2 \mathrm{~J}$ ) also suggest that nicotine does not alter endothelial function.

We further determined smooth muscle contraction and relaxation in F-E- aortic preparations from saline and nicotine-treated rats. Similar to the above data (Figure $2 \mathrm{H}$ ), phenylephrine induced smooth muscle contractions were not dif-

Table 1. $\mathrm{EC}_{50}$ and $E_{\max }$ values for Phe, $5-\mathrm{HT}, \mathrm{ACh}$, and $\mathrm{SNP}$ in different aorta segments from rats. Data are expressed as mean $\pm \mathrm{SEM}$. $n=8$. ${ }^{\mathrm{b}} P<0.05$, ${ }^{\mathrm{c}} \mathrm{P}<0.01$ vs $\mathrm{F}+\mathrm{E}+$. ${ }^{\mathrm{e}} \mathrm{P}<0.05$ vs $\mathrm{F}+\mathrm{E}-.{ }^{\mathrm{h}} \mathrm{P}<0.05$, ${ }^{\mathrm{i}} \mathrm{P}<0.01$ vs $\mathrm{F}-\mathrm{E}+$. $\mathrm{EC}_{50}$, drug concentration required to induce $50 \%$ effect; $E_{\max }$, the maximum contraction responses (Phe at $10^{-4} \mathrm{~mol} / \mathrm{L} ; 5-\mathrm{HT}$ at $10^{-3.5} \mathrm{~mol} / \mathrm{L}$ ) or relaxant responses ( $\mathrm{ACh}$ at $3 \times 10^{-4} \mathrm{~mol} / \mathrm{L}$; SNP at $10^{-4} \mathrm{~mol} / \mathrm{L}$ ).

\begin{tabular}{|c|c|c|c|c|c|}
\hline & & $\mathrm{F}+\mathrm{E}+$ & $\mathrm{F}-\mathrm{E}+$ & $\mathrm{F}+\mathrm{E}-$ & $\mathrm{F}-\mathrm{E}-$ \\
\hline \multirow[t]{2}{*}{ Phe } & $\mathrm{EC}_{50}(\mu \mathrm{mol} / \mathrm{L})$ & $0.29 \pm 0.048$ & $0.15 \pm 0.02^{b}$ & $0.028 \pm 0.0065^{c}$ & $0.012 \pm 0.0018^{\mathrm{e}}$ \\
\hline & $E_{\max }(\mathrm{g})$ & $3.90 \pm 0.32$ & $5.14 \pm 0.48^{b}$ & $6.71 \pm 0.20^{\circ}$ & $7.09 \pm 0.26^{i}$ \\
\hline 5-HT & $E_{\max }(\mathrm{g})$ & $3.63 \pm 0.59$ & $4.98 \pm 0.48^{b}$ & $6.45 \pm 0.47^{\circ}$ & $6.60 \pm 0.43^{h}$ \\
\hline $\mathrm{ACh}$ & $\mathrm{EC}_{50}(\mu \mathrm{mol} / \mathrm{L})$ & $0.05 \pm 0.01$ & $0.04 \pm 0.009$ & & \\
\hline SNP & $E_{\max }(\%)$ & $107 \pm 6.99$ & $100.25 \pm 0.54$ & & $98.10 \pm 1.19$ \\
\hline
\end{tabular}



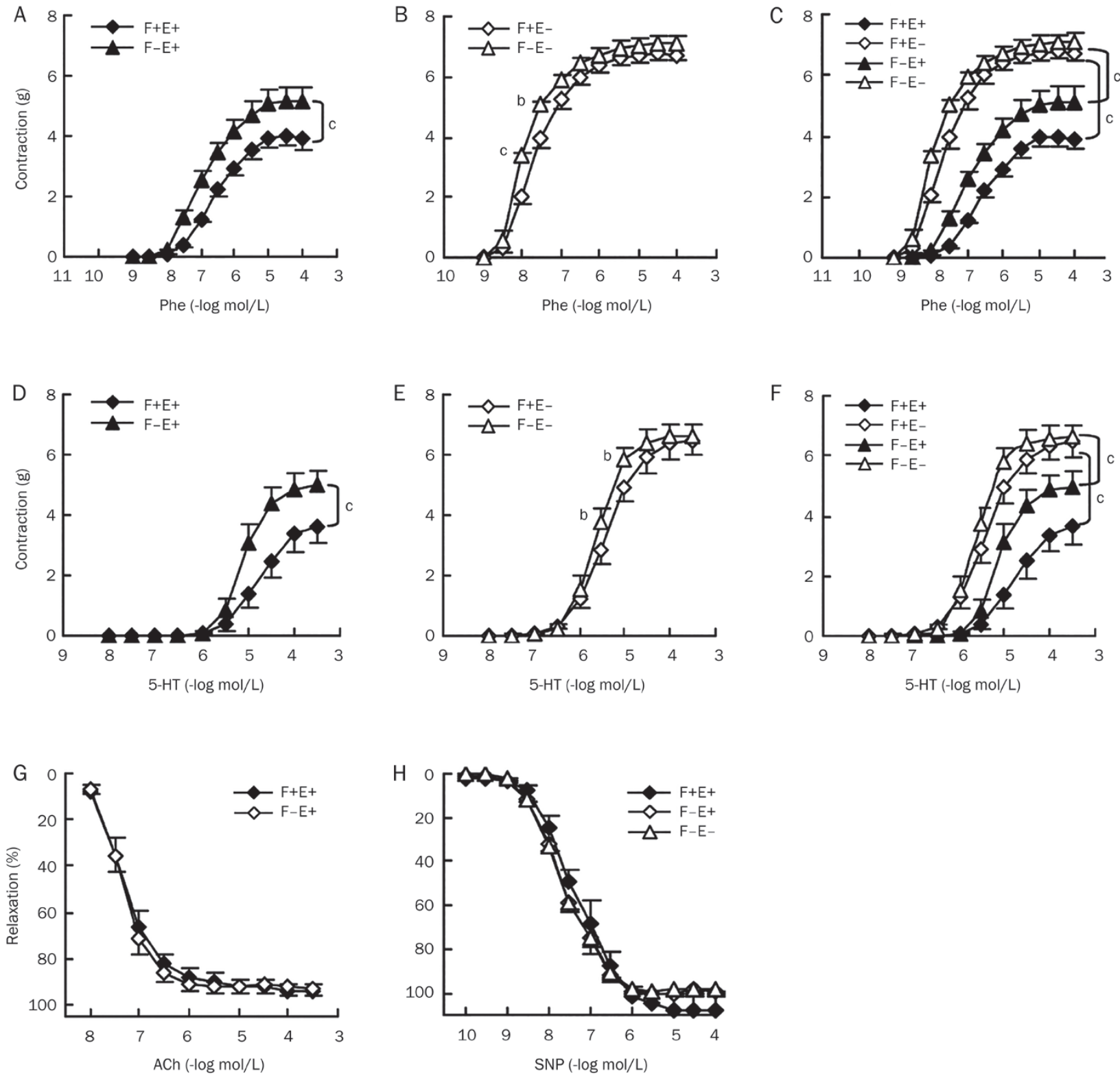

Figure 1. Regulation of adventitial fat on vascular contraction and relaxation in rat aortas. Dose-response curves for aortic contraction in response to Phe (A, B, and C) and 5-HT (D, E, and F). Dose-response curves for aortic relaxation in response to ACh (G) and SNP (H). Aortic rings were precontracted with a single dose of phenylephrine $\left(3 \times 10^{-7} \mathrm{~mol} / \mathrm{L}\right)$ before being exposed to cumulative concentrations of vasorelaxants. Phe, phenylephrine; $5-\mathrm{HT}$, 5-hydroxytryptamine; ACh, acetylcholine; SNP, sodium nitroprusside; F+E+, both adventitial fat and endothelium intact; F-E+, adventitial fat removed and endothelium intact; F+E-, adventitial fat intact and endothelium removed; F-E-, both adventitial fat and endothelium removed. Data are shown as mean \pm SEM. $n=8 .{ }^{\mathrm{b}} P<0.05,{ }^{\mathrm{c}} P<0.01$.

ferent in the saline and nicotine groups (Figure $3 \mathrm{~A}$ and $3 \mathrm{~B}$ ). As expected, the dose-response curve for sodium nitroprusside induced aortic relaxation shifted to the left, further supporting that smooth muscle responses to $\mathrm{NO}$ are enhanced after chronic administration of nicotine in rats (Figure 3C, Table 2).

Chronic nicotine treatment enhances aortic smooth muscle relaxation in rats in a time-dependent manner

We next investigated the time course of chronic nicotine effects on smooth muscle relaxation. F-E- aortic preparations were evaluated. One week of nicotine treatment did not affect the dose-response curve of nitroprusside induced aortic relaxation, whereas nicotine treatment for 3 or 6 weeks significantly shifted nitroprusside dose-response curves to the left (Figure 4, Table 3). It appeared that the differences in smooth muscle relaxation between the saline and nicotine groups became more significant and stable after 6-weeks of treatment (Figure 4). 
A

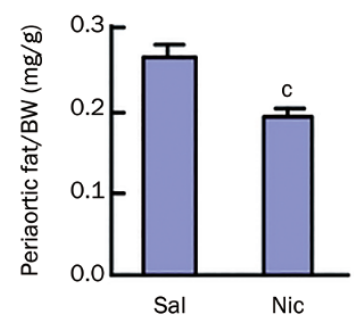

C

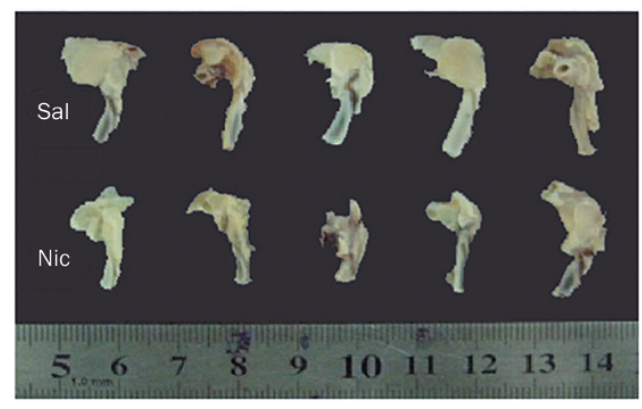

D

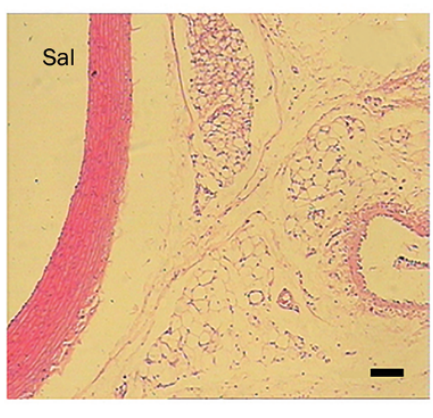

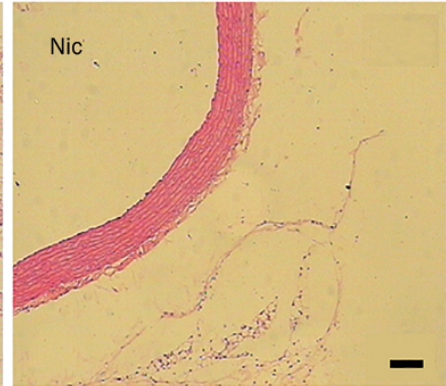

F-E+

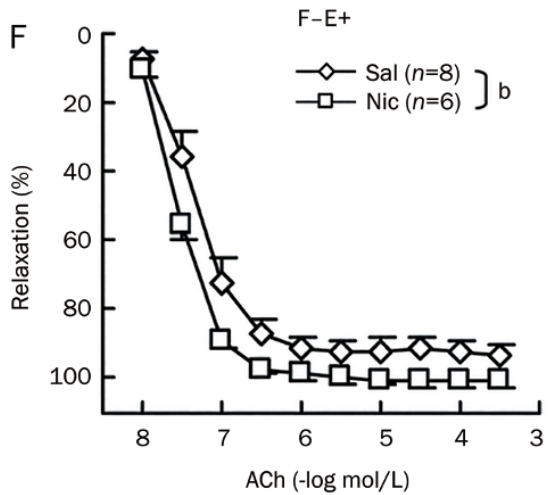

E

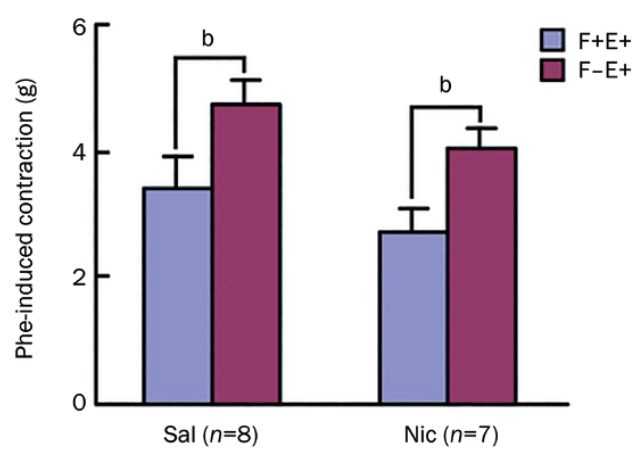

B

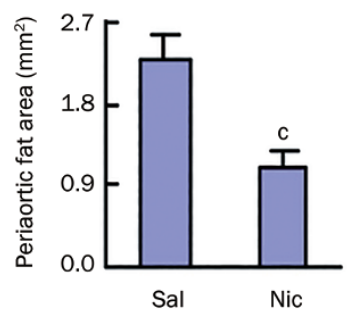

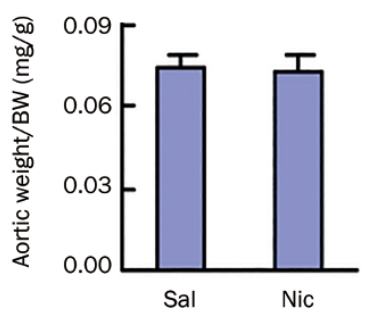

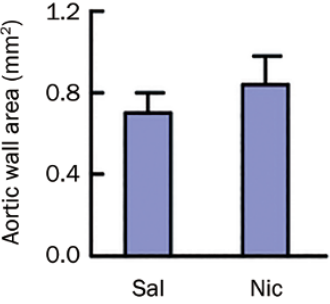


G
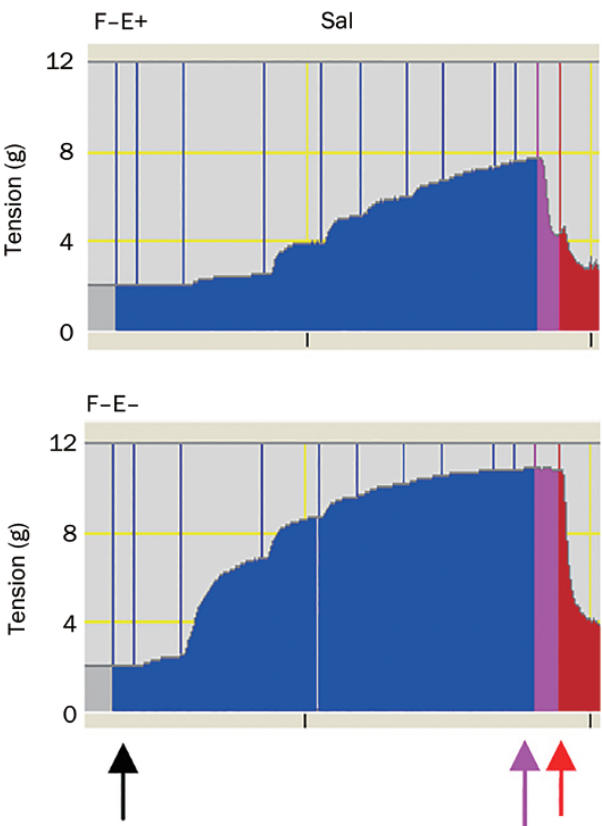

Phe $10^{-9}-3 \times 10^{-5} \mathrm{~mol} / \mathrm{L}$

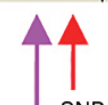

SNP $10^{-4} \mathrm{~mol} /$
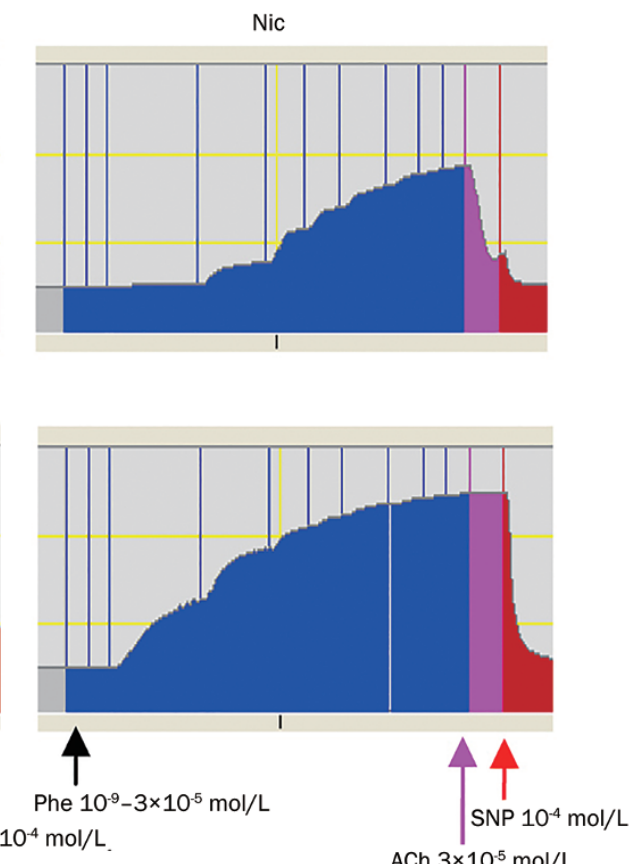

ACh $3 \times 10^{-5} \mathrm{~mol} / \mathrm{L}$

$\mathrm{H}$

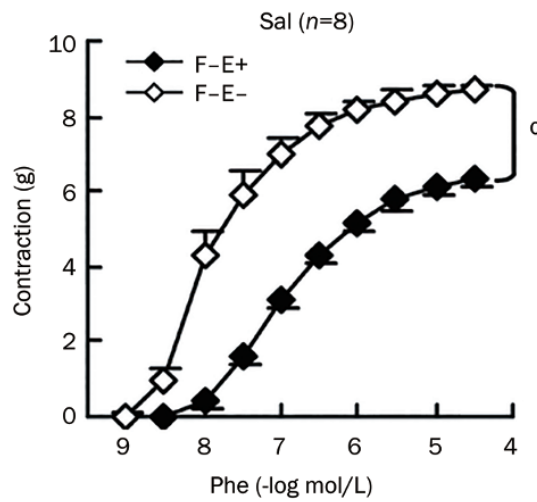

I

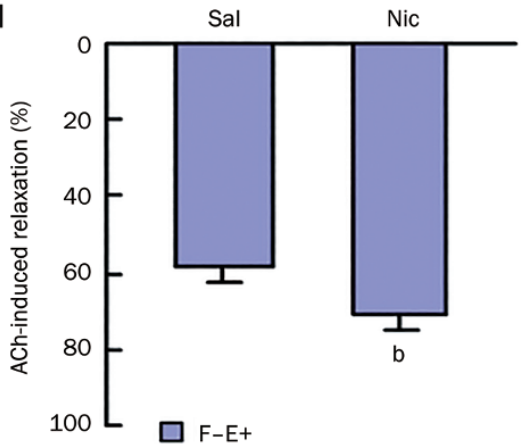

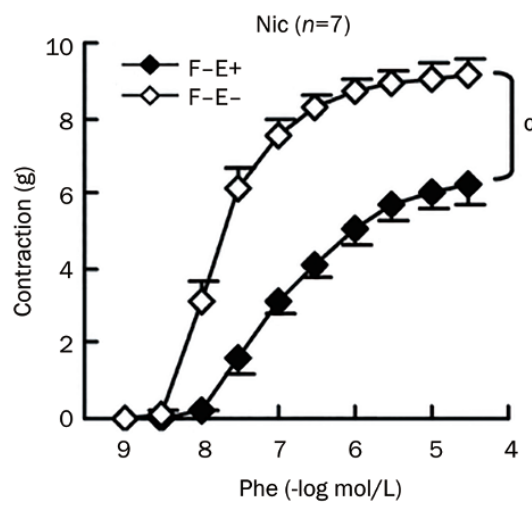

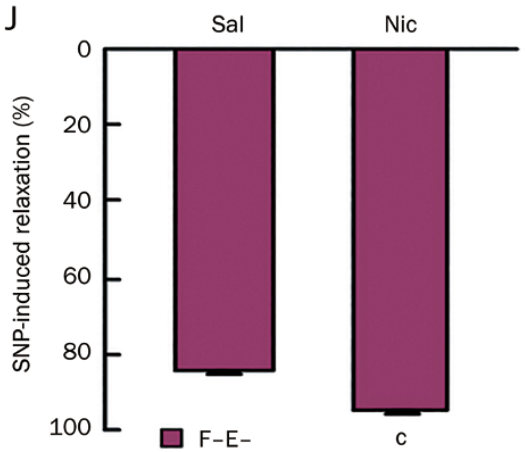

Figure 2G-2J. (G) Representative recordings for Phe-induced aortic pre-contraction and subsequent responses to a single dose of ACh and sodium nitroprusside (SNP). Dose-response curve of Phe-induced aortic pre-contraction $(\mathrm{H})$ and subsequent aortic relaxation induced by a single dose of ACh $\left(3 \times 10^{-6} \mathrm{~mol} / \mathrm{L}\right)(\mathrm{I})$ and SNP $\left(10^{-4} \mathrm{~mol} / \mathrm{L}\right)(\mathrm{J})$ successively. Sal, saline group; Nic, nicotine group; $\mathrm{F}-\mathrm{E}+$, adventitial fat removed and endothelium intact; $\mathrm{F}-\mathrm{E}-$, both adventitial fat and endothelium removed. Data are shown as mean \pm SEM. ${ }^{\mathrm{b}} P<0.05,{ }^{\mathrm{C}} P<0.01$. 
A

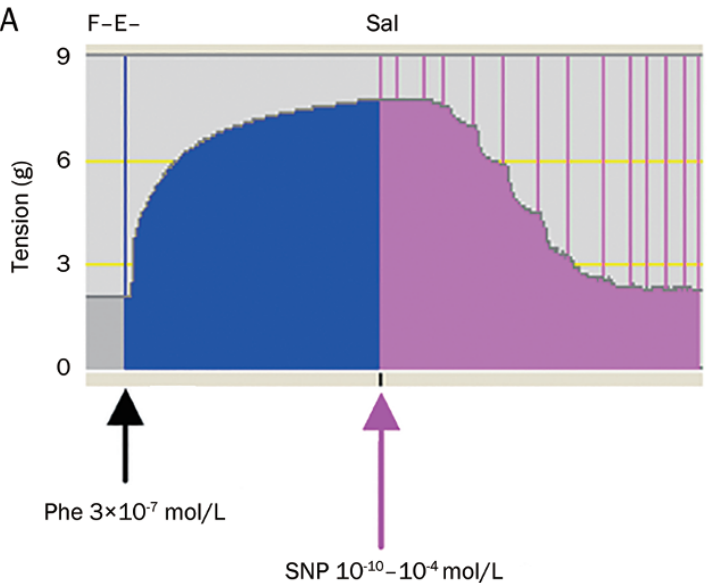

B

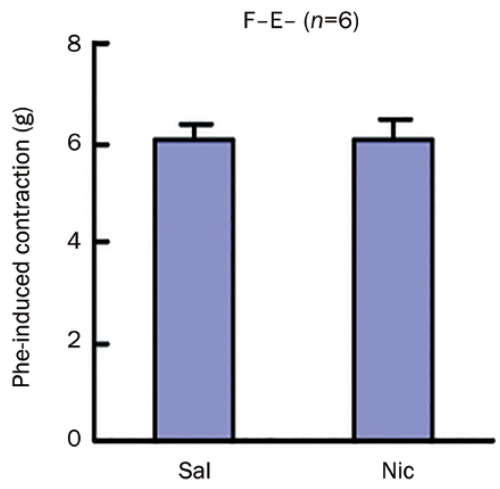

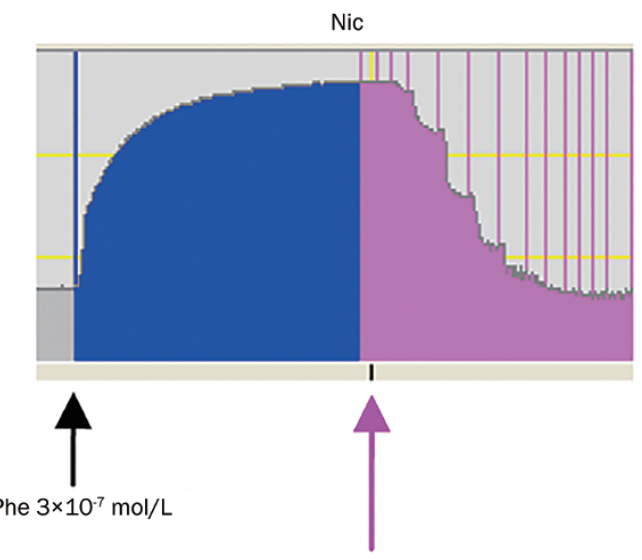

SNP $10^{-10}-10^{-4} \mathrm{~mol} / \mathrm{L}$

C

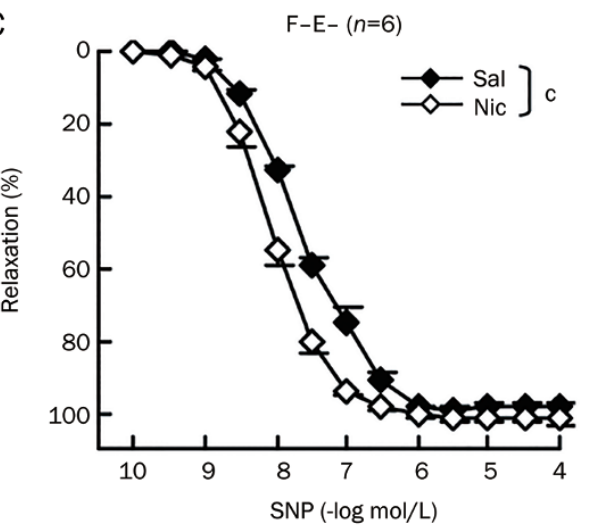

Figure 3. Aortic medial responses to a single dose of phenylephrine (Phe, $3 \times 10^{-7} \mathrm{~mol} / \mathrm{L}$ ) as well as cumulative doses of sodium nitroprusside (SNP). (A) Representative recordings. (B) Aortic contraction induced by a single dose of Phe $\left(3 \times 10^{-7} \mathrm{~mol} / \mathrm{L}\right)$. (C) Dose-response curve of SNP-induced relaxation in aortas pre-contracted with a single dose of Phe $\left(3 \times 10^{-7} \mathrm{~mol} / \mathrm{L}\right)$. Sal, saline group; Nic, nicotine group; F-E-, both adventitial fat and endothelium removed. Data are shown as mean \pm SEM. $n=6$. ${ }^{c} P<0.01$.
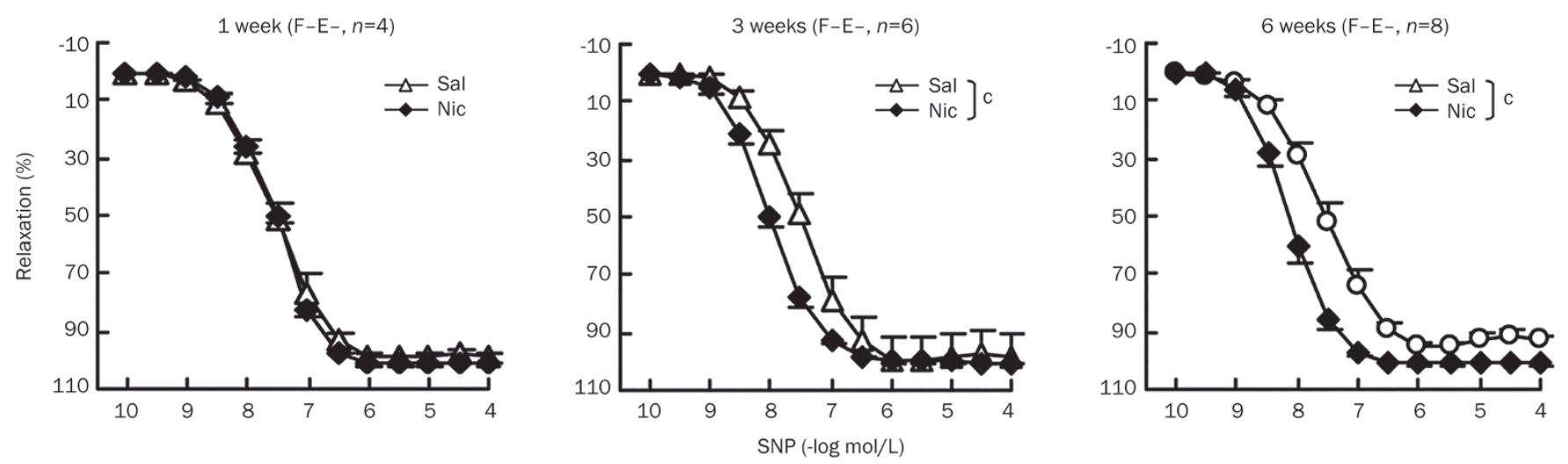

Figure 4. Chronic nicotine treatment enhances aortic smooth muscle relaxation in a time-dependent manner. Dose-response curves of SNP-induced relaxation in aortas pre-contracted with a single dose of Phe $\left(3 \times 10^{-7} \mathrm{~mol} / \mathrm{L}\right)$ after 1 week, 3 weeks and 6 weeks nicotine treatment in Sprague-Dawley rats. Sal, saline group; Nic, nicotine group; F-E-, both adventitial fat and endothelium removed. Data are shown as mean \pm SEM. $n=4-8$. ${ }^{c} P<0.01$. 
Table 3. $E_{50}$ and $E_{\max }$ values for SNP in aortas from rats after 1 week, 3 weeks and 6 weeks saline or nicotine treatment. Data are expressed as mean \pm SEM. $n=4-8$. ${ }^{\circ} P<0.01$ vs Sal. $E_{50}$, drug concentration required to induce $50 \%$ relaxation; $E_{\max }$, the maximum relaxant responses $\left(S N P\right.$ at $10^{-4}$ $\mathrm{mol} / \mathrm{L})$.

\begin{tabular}{|c|c|c|c|c|c|}
\hline & & \multicolumn{2}{|c|}{ Sal (F-E-) } & \multicolumn{2}{|c|}{$\mathrm{Nic}(\mathrm{F}-\mathrm{E}-)$} \\
\hline & & $\mathrm{EC}_{50}(\mathrm{nmol} / \mathrm{L})$ & $E_{\max }(\%)$ & $\mathrm{EC}_{50}(\mathrm{nmol} / \mathrm{L})$ & $E_{\max }(\%)$ \\
\hline 1 week & SNP & $32.50 \pm 7.50$ & $99.33 \pm 0.99$ & $30.00 \pm 4.08$ & $101.70 \pm 0.58$ \\
\hline 6 weeks & SNP & $33.75 \pm 8.22$ & $92.94 \pm 1.91$ & $6.00 \pm 0.63^{c}$ & $101.15 \pm 0.30^{c}$ \\
\hline
\end{tabular}

Chronic nicotine treatment enhances aortic smooth muscle relaxation induced by sodium nitroprusside through a cGMPdependent PKG pathway

We further investigated the underlying mechanism in F-Eaortic preparations from saline and nicotine-treated rats. Endothelium independent relaxation induced by sodium nitroprusside is mediated via NO, an intracellular byproduct of sodium nitroprusside. NO can in turn induce smooth muscle relaxation through a cGMP-dependent or independent pathway ${ }^{[23]}$. We explored whether the differential relaxation between the saline and nicotine group was due to alterations in the cGMP-dependent pathway. NO increases the concentration of cGMP by activation of the soluble guanylyl cyclase (sGC). Pretreatment with the sGC inhibitor, ODQ ${ }^{[24]}$, markedly reduced sodium nitroprusside induced relaxation in both saline and nicotine groups and abolished the significant difference in relaxation between the two groups (Figure $5 \mathrm{~A}$, Table 4). When we used a cGMP analog, 8-Br-cGMP ${ }^{[25]}$ instead of sodium nitroprusside to induce relaxation, the dose-response curve for 8-Br-cGMP induced aortic relaxations significantly shifted to the left similar to sodium nitroprusside in the nicotine treated group (Figure $5 \mathrm{~B}$ ). The $\mathrm{EC}_{50}$ values of 8 -Br-cGMP for aortic relaxation were $5 \times 10^{-5} \mathrm{~mol} / \mathrm{L}$ for the saline group and $3 \times 10^{-5} \mathrm{~mol} / \mathrm{L}$ for the nicotine group $(P<0.05$ between two groups). The maximal relaxation values attained with 8 -Br-cGMP were also increased by $13 \%$ in the nicotine group ( $P<0.01$ between two groups). Moreover, pretreatment with the cGMP dependent protein kinase (PKG) inhibitor Rp-
A

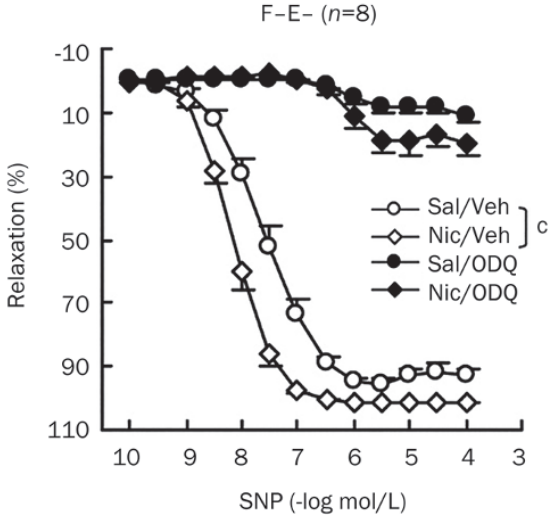

D

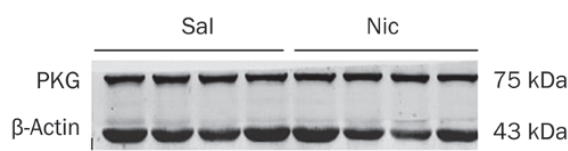

B
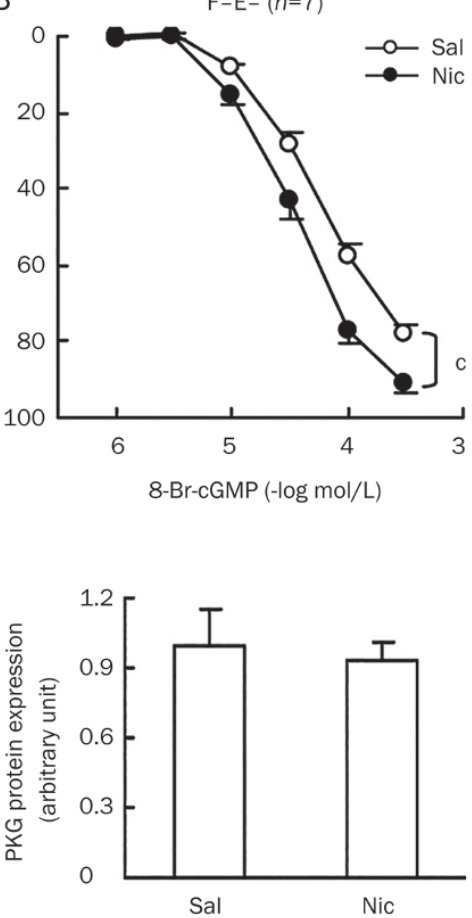

C

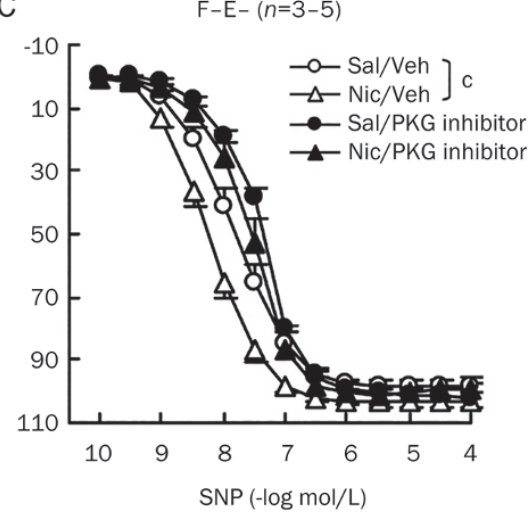

$E$

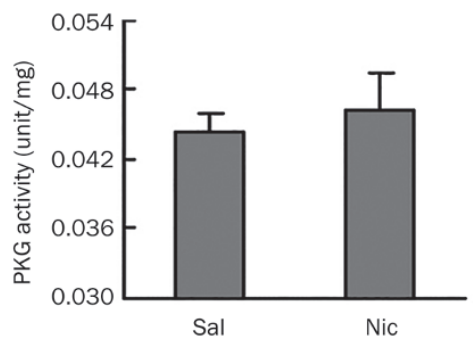

Figure 5. Chronic nicotine treatment enhances aortic smooth muscle relaxation induced by sodium nitroprusside through cGMP-dependent PKG pathway. Aortic medial relaxation induced by cumulative doses of sodium nitroprusside (SNP) in the absence and presence of soluble guanylyl cyclase inhibitor, ODQ (3 $\mu \mathrm{mol} / \mathrm{L})(\mathrm{A})$ and cGMP dependent protein kinase (PKG) inhibitor, Rp-8-Br-PET-cGMP (30 $\mu$ mol/L) (C). (B) Aortic medial responses to cumulative doses of cGMP analog, 8-Br-cGMP. (D) Western blot analysis to detect PKG protein expression in aortic media, $\beta$-actin expression as a loading control. (E) PKG activity analysis in aortic media. Sal, saline group; Nic, nicotine group; F-E-, both adventitial fat and endothelium removed. Data are shown as mean \pm SEM. $n=3-8 .{ }^{\circ} P<0.01$. 
Table 4. $E_{50}$ and $E_{\max }$ values for SNP in the absence and presence of inhibitors in aortas from saline and nicotine treated rats. Data are expressed as mean \pm SEM. $n=3-8 .{ }^{b} P<0.05,{ }^{c} P<0.01$ vs Sal. $E_{50}$, drug concentration required to induce $50 \%$ relaxation; $E_{\max }$, the maximum relaxant responses (SNP at $\left.10^{-4} \mathrm{~mol} / \mathrm{L}\right)$.

\begin{tabular}{llcccc}
\hline & & \multicolumn{2}{c}{ Control } & \multicolumn{2}{c}{ Treatment } \\
& & $E_{50}(\mathrm{nmol} / \mathrm{L})$ & $E_{\max }(\%)$ & $E_{50}(\mathrm{nmol} / \mathrm{L})$ & $E_{\max }(\%)$ \\
\hline \multirow{2}{*}{ Sal (F-E-) } & ODQ & $32.50 \pm 8.61$ & $92.91 \pm 1.89$ & $2863.50 \pm 895.01$ & $10.96 \pm 2.25$ \\
& PKG inhibitor & $12.80 \pm 2.25$ & $99.38 \pm 0.31$ & $43.33 \pm 3.33$ & $101.93 \pm 1.92$ \\
Nic (F-E-) & ODQ & $6.00 \pm 0.68^{\mathrm{b}}$ & $101.03 \pm 0.30^{\circ}$ & $2625.00 \pm 993.69$ & $19.45 \pm 3.74$ \\
& PKG inhibitor & $6.00 \pm 1.27^{\mathrm{b}}$ & $104.05 \pm 1.73^{\mathrm{b}}$ & $27.50 \pm 7.50$ & $99.28 \pm 3.62$ \\
\hline
\end{tabular}

8-Br-PET-cGMP ${ }^{[26]}$ not only shifted the sodium nitroprussideinduced relaxation to the right in both groups, but also abolished the relaxation difference between two groups (Figure 5C, Table 4). Thus, nitroprusside-induced relaxation enhancement by chronic nicotine treatment occurs in a cGMP dependent PKG pathway and the affected targets are not upstream of PKG. We then examined PKG protein expression and activity (Figure 5D and 5E). No significant differences were found between saline and nicotine treated groups. These results indicate that the related targets affected by chronic nicotine treatment are located in the PKG downstream pathway.

\section{Discussion}

In the present study, we studied the effect of chronic nicotine exposure on vascular function and sought to identify the mechanisms underlying this effect. We found that chronic nicotine treatment in adult animals enhances aortic smooth muscle relaxation, without alterations in adventitial fat and endothelium function or smooth muscle contraction. Detailed exploration of the cGMP-dependent PKG relaxation pathway revealed that PKG downstream targets are responsible for the nicotine-induced enhancement of vascular relaxation.

In our study, chronic nicotine treatment did not affect endothelium dependent relaxation and anticontractile function in the rat aorta. Consistent with our results, Zhang et al noted that nicotine did not damage endothelial cells and did not reduce endothelium-dependent dilatation in rat and $\operatorname{man}^{[27]}$. Some previous reports correlated nicotine with impaired endothelium dependent relaxation, mainly due to free radical production ${ }^{[1]}$. However, these studies mainly focused on resistance and small arteries. Some of them observed the effect of cigarette extractions rather than that of nicotine. Furthermore, in most previous reports, the duration of nicotine treatment was relatively short or acute. Studies have revealed that the effects of chronic nicotine exposure differ from those of acute exposure due to the complex characteristics of $\mathrm{nAChRs}{ }^{[3,4]}$. The duration of nicotine treatment in our experiment was six weeks and more accurately reflected the long-term effect of nicotine on vascular function.

However, based on the present results, there is the possibility that basal NO release from endothelium rather than acetylcholine induced NO release might be reduced in the nicotine group. Similar degrees of relaxation enhancement induced by either acetylcholine or sodium nitroprusside were observed in the nicotine group (Figure 2I and 2J), suggesting an equal amount of NO release induced by acetylcholine stimulation in the saline and nicotine groups. However, phenylephrine induced contractions in aortas with and without endothelium reflect basal NO release (Figure $2 \mathrm{H}$ ). If basal NO release was the same between the nicotine and saline groups, the anticontractile effect in the nicotine group should have been stronger. In fact, there was a trend towards enhanced anticontractile effect in the nicotine group, but it was not statistically significant. Thus, chronic nicotine treatment may reduce basal NO production.

Regarding nicotine effect on adventitial fat, only one previous study observed an effect of prenatal nicotine exposure on the amount and function of postnatal periaortic fat ${ }^{[12]}$. The study demonstrated that prenatal nicotine exposure increased the amount of periaortic fat and impaired the anti-contractile function of periaortic fat in the offspring. However, results from our study in adult rats indicated that chronic nicotine treatment did not alter the anti-contractile function of adventitial fat, in spite of the decreased amount of the fat. Two main factors probably contribute to this discrepancy. First, the remaining adventitial fat still possessed anticontractile function ${ }^{[28]}$. Second, the function of adventitial fat probably changed and may involve some mechanism of compensation to supplement the loss due to reduced adventitial fat. It is very likely that fat may be more effective after nicotine treatment. Nicotine has a direct effect on the function of adipocytes. Many types of nicotinic acetylcholine receptors have been reported to be expressed in rat adipocytes ${ }^{[3]}$. In fact, it has been reported that chronic nicotine treatment improves fat insulin sensitivity ${ }^{[29]}$, suggesting a more effective function of fat after nicotine treatment.

The most important finding of our study is that chronic nicotine treatment enhances endothelium independent smooth muscle relaxation, without altering smooth muscle contraction. This effect has been demonstrated in several of our experiments. We also found that the smooth muscle relaxation enhancing effect of nicotine was time dependent. The extent of relaxation gradually increased over the 6-week duration of nicotine treatment in Sprague-Dawley rats. The time point of six weeks after treatment was suitable for further mechanistic studies, because at this time the relaxation difference 
between the saline and nicotine groups was significant and stable. Zou et al reported that nicotine induced endothelium dependent relaxation in aortic preparations from both spontaneously hypertensive and Wistar-Kyoto normotensive rats via the activation of $a 7-n A C h R^{[8]}$. However, quite different from our findings, they only observed the direct and acute effect of nicotine in isolated aortas. While in our model, nicotine did not enhance relaxation of the aorta after a 1 week treatment. Moreover, while they found that a7-nAChR mediated vasorelaxation was endothelium dependent, in our model, the relaxation enhancing effect of nicotine was endothelium independent.

In agreement with our results, the basal blood pressure is usually slightly lower in smokers ${ }^{[30,31]}$. One study also evaluated forearm blood flow in healthy smokers and non-smokers and found that smokers were more sensitive to endothelium independent relaxation stimulus than non-smokers, though the mechanism was unclear ${ }^{[31]}$. Contrary to our results, another study in cerebral arterioles found that nicotine impaired NO-induced endothelium independent relaxation ${ }^{[32]}$. Their experiments differed in that they used a relatively higher nicotine dose $\left(4.5 \mathrm{mg} \cdot \mathrm{kg}^{-1} \cdot \mathrm{d}^{-1}\right)$, a shorter treatment duration (2-3 weeks) and female rats. In addition, Wang et al reported that chronic nicotine exposure increased canonical transient receptor potential (TRPC) expression in pulmonary arterial smooth muscle ${ }^{[33]}$, which contributed to the increases in basal intracellular concentration of $\mathrm{Ca}^{2+}$, constriction and remodeling of pulmonary arterial smooth muscle. In addition to the difference in administration, the nicotine dose and treatment duration, different features of various vascular beds probably account for the disparity. TRPC4 and TRPC6 have been shown to be expressed predominantly in rat pulmonary artery smooth muscle. However, we previously noted that mRNA expression of TRPC4 and TRPC6 were not at detectable levels in rat aortic smooth muscle of rat either in the control or nicotine treated group (data not shown).

Current results suggest that a PKG downstream target is responsible for the nicotine-induced enhancement of vascular relaxation. Two main mechanisms involved in PKG-mediated smooth muscle relaxation are cytosolic $\mathrm{Ca}^{2+}$ concentration reduction and $\mathrm{Ca}^{2+}$ desensitization ${ }^{[34]}$. In addition, PKG can also mediate vascular relaxation through thin filament regulation $^{[35,36]}$. It is not likely that nicotine augments relaxation through $\mathrm{Ca}^{2+}$ desensitization, because $\mathrm{Ca}^{2+}$ dependent contractions induced by phenylephrine or 5-hydroxytryptamine are not altered. Nicotine has been reported to regulate PKG downstream target $\mathrm{BK}_{\mathrm{Ca}}$ in cerebral arterioles ${ }^{[32]}$. However, further organ bath studies eliminated the involvement of most potassium channels expressed in vascular smooth muscle cells, including $\mathrm{BK}_{\mathrm{Ca}}$ (data not shown). Another important $\mathrm{Ca}^{2+}$ dependent target sarcoplasmic/endoplasmic reticulum $\mathrm{Ca}^{2+}$-ATPase (SERCA) was also eliminated. Future studies are needed to explore other $\mathrm{Ca}^{2+}$ dependent targets such as the regulator of $G$ protein signaling (RGS) proteins and inositol 1,4,5-trisphosphate receptor $\left(\mathrm{IP}_{3} \mathrm{R}\right)$-associated cGMP kinase substrate $\left(\right.$ IRAG) ${ }^{[34]}$. Meanwhile, heat shock protein 20
(HSP20), an important protein affecting thin filament regulation $^{[37,38]}$, should also be considered. HSP20 is constitutively expressed in vascular smooth muscle and can be phosphorylated by cyclic nucleotide-dependent protein kinases ${ }^{[36,39,40]}$. Phosphorylation of HSP20 is very effective for smooth muscle relaxation. Increases in the expression or phosphorylation of HSP20 under different physiological and pathophysiological conditions correlate with enhanced smooth muscle relaxation $^{[35]}$.

We report for the first time that nicotine enhances the sensitivity of the NO relaxation pathway in vascular smooth muscle. This effect of nicotine may be mediated through a known or unknown PKG downstream pathway. These findings contribute to a deeper understanding of nicotine pharmacology and its involvement in the vascular relaxation pathways. Considering that enhanced vascular relaxation or sensitivity of the NO/cGMP/PKG pathway benefits many clinical diseases, our study presents valuable information that could be applied to the development of new clinical therapeutic approaches to these diseases.

\section{Acknowledgements}

This work was supported by grants from the National Natural Science Foundation of China (No 81102487 to Tianying XU and 81130061 and 81373414 to Chao-yu MIAO), and the National Science and Technology Major Project (No 2009ZX09303-002 to Chao-yu MIAO).

\section{Author contribution}

Chao-yu MIAO designed the study and revised the manuscript; Tian-ying XU wrote the manuscript; Tian-ying XU, Xiao-hong LAN, and Yun-feng GUAN performed the animal treatment and the organ bath experiments; Sai-long ZHANG and Xia WANG contributed to the molecular biology experiments.

\section{References}

1 Hanna ST. Nicotine effect on cardiovascular system and ion channels. J Cardiovasc Pharmacol 2006; 47: 348-58.

$2 \mathrm{Vu}$ CU, Siddiqui JA, Wadensweiler P, Gayen JR, Avolio E, Bandyopadhyay GK, et al. Nicotinic cholinergic receptors in glucose homeostasis: the acute hyperglycemic and chronic insulin-sensitive effects of nicotine suggest dual opposing roles of the receptors in male mice. Endocrinology 2014; 155: 3793-805.

3 Liu RH, Mizuta M, Matsukura S. The expression and functional role of nicotinic acetylcholine receptors in rat adipocytes. J Pharmacol Exp Ther 2004; 310: 52-8.

4 Gahring LC, Rogers SW. Neuronal nicotinic acetylcholine receptor expression and function on nonneuronal cells. AAPS J 2005; 7: E88594.

5 Xu TY, Guo LL, Wang P, Song J, Le YY, Viollet B, et al. Chronic exposure to nicotine enhances insulin sensitivity through alpha7 nicotinic acetylcholine receptor-STAT3 pathway. PLoS One 2012; 7: e51217.

6 Wada T, Naito M, Kenmochi H, Tsuneki H, Sasaoka T. Chronic nicotine exposure enhances insulin-induced mitogenic signaling via upregulation of alpha7 nicotinic receptors in isolated rat aortic smooth muscle cells. Endocrinology 2007; 148: 790-9.

7 Hambsch B, Keyworth H, Lind J, Otte DM, Racz I, Kitchen I, et al. 
Chronic nicotine improves short-term memory selectively in a G72 mouse model of schizophrenia. Br J Pharmacol 2014; 171: 1758-71.

8 Zou Q, Leung SW, Vanhoutte PM. Activation of nicotinic receptors can contribute to endothelium-dependent relaxations to acetylcholine in the rat aorta. J Pharmacol Exp Ther 2012; 341: 756-63.

9 Arrick DM, Mayhan WG. Acute infusion of nicotine impairs nNOSdependent reactivity of cerebral arterioles via an increase in oxidative stress. J Appl Physiol (1985) 2007; 103: 2062-7.

10 Xiao D, Huang X, Lawrence J, Yang S, Zhang L. Fetal and neonatal nicotine exposure differentially regulates vascular contractility in adult male and female offspring. J Pharmacol Exp Ther 2007; 320: 654-61.

11 Xiao D, Xu Z, Huang X, Longo LD, Yang S, Zhang L. Prenatal genderrelated nicotine exposure increases blood pressure response to angiotensin II in adult offspring. Hypertension 2008; 51: 1239-47.

12 Gao YJ, Holloway AC, Zeng ZH, Lim GE, Petrik JJ, Foster WG, et al. Prenatal exposure to nicotine causes postnatal obesity and altered perivascular adipose tissue function. Obes Res 2005; 13: 687-92.

13 Lan XH, Xu TY, Miao CY. Establishment and evaluation of a nicotinetreatment and -withdrawal rat model. Acad J Sec Milit Med Univ 2008; 29: 156-61.

14 Guan YF, Chen RH, Wang P, Qin Y, Su DF, Miao CY. Hypertonic and isotonic potassium solutions have different effects on vessel contractility resulting in differences in optimal resting tension in rat aorta. Acta Pharmacol Sin 2007; 28: 643-50.

15 Wang P, Xu TY, Guan YF, Su DF, Fan GR, Miao CY. Perivascular adipose tissue-derived visfatin is a vascular smooth muscle cell growth factor: role of nicotinamide mononucleotide. Cardiovasc Res 2009; 81: 370-80.

16 Wang P, Xu TY, Guan YF, Zhao Y, Li ZY, Lan XH, et al. Vascular smooth muscle cell apoptosis is an early trigger for hypothyroid atherosclerosis. Cardiovasc Res 2014; 102: 448-59.

17 Wang P, Xu TY, Guan YF, Tian WW, Viollet B, Rui YC, et al. Nicotinamide phosphoribosyltransferase protects against ischemic stroke through SIRT1-dependent adenosine monophosphate-activated kinase pathway. Ann Neurol 2011; 69: 360-74.

18 Zheng X, Ying L, Liu J, Dou D, He Q, Leung SW, et al. Role of sulfhydryldependent dimerization of soluble guanylyl cyclase in relaxation of porcine coronary artery to nitric oxide. Cardiovasc Res 2011; 90 : 565-72.

19 Priestman MA, Sun L, Lawrence DS. Dual wavelength photoactivation of CAMP- and CGMP-dependent protein kinase signaling pathways. ACS Chem Biol 2011; 6: 377-84.

20 Guo LW, Ruoho AE. Inhibition of cGMP-dependent protein kinase by the regulatory subunit of photoreceptor cGMP phosphodiesterase. Neurosci Lett 2006; 401: 252-5.

21 Miao CY, Xie HH, Zhan LS, Su DF. Blood pressure variability is more important than blood pressure level in determination of end-organ damage in rats. J Hypertens 2006; 24: 1125-35.

22 Lohn M, Dubrovska G, Lauterbach B, Luft FC, Gollasch M, Sharma AM. Periadventitial fat releases a vascular relaxing factor. FASEB J 2002; 16: $1057-63$.

23 Wanstall JC, Homer KL, Doggrell SA. Evidence for, and importance of, cGMP-independent mechanisms with $\mathrm{NO}$ and NO donors on blood vessels and platelets. Curr Vasc Pharmacol 2005; 3: 41-53.
24 El-Awady MS, Smirnov SV, Watson ML. Desensitization of the soluble guanylyl cyclase/cGMP pathway by lipopolysaccharide in rat isolated pulmonary artery but not aorta. Br J Pharmacol 2008; 155: 116473.

25 Szadujkis-Szadurska K, Grzesk G, Szadujkis-Szadurski L, Gajdus $M$, Matusiak G. Role of nitric oxide and cGMP in the modulation of vascular contraction induced by angiotensin II and Bay K8644 during ischemia/reperfusion. Exp Ther Med 2013; 5: 616-20.

26 Butt E, Pohler D, Genieser HG, Huggins JP, Bucher B. Inhibition of cyclic GMP-dependent protein kinase-mediated effects by (Rp)-8bromo-PET-cyclic GMPS. Br J Pharmacol 1995; 116: 3110-6.

27 Zhang JY, Cao YX, Xu CB, Edvinsson L. Lipid-soluble smoke particles damage endothelial cells and reduce endothelium-dependent dilatation in rat and man. BMC Cardiovasc Disord 2006; 6: 3.

28 Verlohren S, Dubrovska G, Tsang SY, Essin K, Luft FC, Huang Y, et al. Visceral periadventitial adipose tissue regulates arterial tone of mesenteric arteries. Hypertension 2004; 44: 271-6.

29 Wang X, Yang Z, Xue B, Shi H. Activation of the cholinergic antiinflammatory pathway ameliorates obesity-induced inflammation and insulin resistance. Endocrinology 2011; 152: 836-46.

30 Wennmalm A, Benthin G, Granstrom EF, Persson L, Petersson AS, Winell S. Relation between tobacco consumption and urinary excretion of thromboxane A2 and prostacyclin metabolites in 756 randomly sampled young men. Adv Prostaglandin Thromboxane Leukot Res 1991; 21B: 615-8.

31 Rangemark C, Wennmalm A. Endothelium-dependent and -independent vasodilation and reactive hyperemia in healthy smokers. J Cardiovasc Pharmacol 1992; 20 Suppl 12: S198-201.

32 Gerzanich V, Zhang F, West GA, Simard JM. Chronic nicotine alters NO signaling of $\mathrm{Ca}^{2+}$ channels in cerebral arterioles. Circ Res 2001; 88: 359-65.

33 Wang J, Chen Y, Lin C, Jia J, Tian L, Yang K, et al. Effects of chronic exposure to cigarette smoke on canonical transient receptor potential expression in rat pulmonary arterial smooth muscle. Am J Physiol Cell Physiol 2014; 306: C364-73.

34 Hofmann F, Feil R, Kleppisch T, Schlossmann J. Function of cGMPdependent protein kinases as revealed by gene deletion. Physiol Rev 2006; 86: 1-23.

35 Dreiza CM, Komalavilas P, Furnish EJ, Flynn CR, Sheller MR, Smoke $\mathrm{CC}$, et al. The small heat shock protein, HSPB6, in muscle function and disease. Cell Stress Chaperones 2010; 15: 1-11.

36 Mymrikov EV, Seit-Nebi AS, Gusev NB. Large potentials of small heat shock proteins. Physiol Rev 2011; 91: 1123-59.

37 Edwards HV, Cameron RT, Baillie GS. The emerging role of HSP2O as a multifunctional protective agent. Cell Signal 2011; 23: 1447-54.

38 Salinthone S, Tyagi M, Gerthoffer WT. Small heat shock proteins in smooth muscle. Pharmacol Ther 2008; 119: 44-54.

39 Beall A, Bagwell D, Woodrum D, Stoming TA, Kato K, Suzuki A, et al. The small heat shock-related protein, HSP20, is phosphorylated on serine 16 during cyclic nucleotide-dependent relaxation. J Biol Chem 1999; 274: 11344-51.

40 Rembold CM, Foster DB, Strauss JD, Wingard CJ, Eyk JE. cGMPmediated phosphorylation of heat shock protein 20 may cause smooth muscle relaxation without myosin light chain dephosphorylation in swine carotid artery. J Physiol 2000; 524 Pt 3: 865-78. 